\title{
Prevalence and Associated Anomalies in Gastroschisis and Omphalocele Cases in Villa Clara, Cuba: A 30-Year Series from 1990 to 2019
}

\author{
Noel Taboada Lugo ${ }^{*}$, Ana E Algora Hernández², Manuela Herrera Martínez ${ }^{3}$, María E de la \\ Torre Santos ${ }^{4}$, Oriali Piedra Morales ${ }^{5}$ and Eliecer Anoceto Armiñana ${ }^{6}$ \\ ${ }^{1}$ Master of Sciences, Medical Doctor, Terminal Professional Degree in Clinical Genetics, Associated Professor and Researcher at \\ the Villa Clara Medical University, Cuba
}

${ }^{2}$ Master of Sciences, Medical Doctor, Terminal Professional Degree in Clinical Genetics, Associated Professor of Medical Genetics at the Villa Clara Medical University, Cuba

${ }^{3}$ PhD. Master in Sciences. Terminal Professional Degree in Clinical Genetics. Full Professor and Researcher at the Villa Clara Medical University, Cuba.

${ }^{4}$ Terminal Professional Degree in Clinical Genetics, Full Professor and Researcher at the Villa Clara Medical University, Cuba ${ }^{5}$ Medical doctor. Terminal Professional Degree in Radiology, Cuba

${ }^{6}$ Medical Doctor, Terminal Professional Degree in Pathological Anatomy, Associated Professor of Medical Genetics at the Villa Clara Medical University, Cuba

*Corresponding author: Noel Taboada Lugo, Master of Sciences, Medical Doctor, Terminal Professional Degree in Clinical Genetics, Associated Professor and Researcher at the Villa Clara Medical University, Cuba

\section{ARTICLE INFO}

Received: 蔧 June 01, 2021

Published: 㓞 June 11, 2021

Citation: Noel Taboada Lugo, Ana E Algora Hernández, Manuela Herrera Martínez, María E de la Torre Santos, Oriali Piedra Morales, Eliecer Anoceto Armiñana. Prevalence and Associated Anomalies in Gastroschisis and Omphalocele Cases in Villa Clara, Cuba: A 30-Year Series from 1990 to 2019. Biomed J Sci \& Tech Res 36(3)-2021. BJSTR. MS.ID.005854.

Keywords: Abdominal wall defects; Gastroschisis; Omphalocele; Karyotyping; Anomalies; Cuba

\section{ABSTRACT}

Background: Gastroschisis and omphalocele are the most common anterior abdominal wall defects. The aims of our study were to describe the prevalence trends of these congenital anterior abdominal wall defects and to determine the frequency and type of associated congenital anomalies.

Methods: A retrospective, observational study, with data obtained by the Cuban Registries of Congenital Malformations; was conducted in the Cuban province of Villa Clara from 1990 to 2019.

Results: A total of 158 cases were identified, 93 of them (59\%) with gastroschisis and 53 with omphalocele. An increasing trend in the prevalence rate per 10,000 births of the studied abdominal wall defects over the thirty studied years, from 3.83 in 1990 to 7.47 in 2019, was observed. The prevalence rate of gastroschisis (per 10,000 births) during the study timeframe was twofold those of omphalocele ( 4.8 and 2.7 respectively). The majority of gastroschisis cases did not have additional anomalies (80/93 [86\%]). There was a statistically significant difference between the proportions of isolated and associated cases. $(\mathrm{p}<0.01)$. Omphalocele cases were more likely to be diagnosed with at least one other congenital defect than those with gastroschisis $(25 / 53$ [47\%] vs. 12/93 [13\%].

Conclusions: Arise in anterior abdominal wall defects prevalence has been noted in recent decades in Villa Clara province. The present study revealed that omphalocele cases were more likely to have other congenital defects, predominantly in musculoskeletal and cardiovascular systems, besides chromosomal aberrations. In our study a very high rate of termination of pregnancy is observed among abdominal wall defects cases. 


\section{Introduction}

Anterior abdominal wall defects are a common cause of morbidity and even mortality. These include the most common congenital anterior abdominal wall defects (AWD): gastroschisis (GS) and omphalocele (OM) or exomphalos. GS is a congenital defect (CD) where the small intestine, part of the large intestine and occasionally other abdominal organs protrude through a lateral defect in the ventral abdomen without any protective membrane, whereas $\mathrm{OM}$ is an amnion covered sac enclosing a range of viscera from a few loops of midgut to the entire midgut, liver and spleen [1-3]. Such defects were initially described in the first century AD by the Roman physician Aulus Cornelius Celsus but until the middle part of the $20^{\text {th }}$ century, no real distinction was made between the two [3]. The term gastroschisis was first used by the Italian pathologist Cesare Taruffi in 1894 and translates from Greek as 'belly cleft'. The etiology of this CD is unclear, and its actual pathogenesis is not known. Failure of migration and fusion of embryonic ventral body folds (particularly from the right) has been suggested together with disruption of either the umbilical vein or the vitelline (omphalomesenteric) artery resulting in infarction at the base of the umbilicus $[3,4]$.

Recent theories challenge this last pathogenic mechanism and propose that GS results from faulty embryogenesis with failure of incorporation of the yolk sac and vitelline structures into the umbilical stalk, resulting in an AWD, through which the midgut egresses into the amniotic cavity. Thus, GS has no covering membrane [4]. It is unclear why the failure of fusion of embryonic folds occurs but is likely to be due to disruption of the delicate balance of cellular apoptosis and proliferation during this early stage of development. Although the specific insult is as yet unknown, observational studies into genetic and environmental factors supplemented by animal models have allowed developing a basic framework of associated risk factors [3]. GS is one of the few major CD with well documented increasing birth prevalence in both resource-limited and resource-rich settings. The prevalence of GS in recent decades shows a remarkable and worrying increasing trend worldwide. Current estimates of the prevalence of GS demonstrate an uptrend, from 3.6 per 10,000 births during 1995-2005 to 4.9 per 10,000 births during 2006-2012 [1,4-6].

Reasons for the increasing prevalence in GS are unknown; however, several risk factors are associated with this CD, especially young maternal age. An increasing prevalence of GS among younger mothers, especially under 24 years of age, has consistently been documented, and young maternal age has been recognized as one of the strongest risk factors for GS [7]. The prevalence of GS also differs by maternal race/ethnicity, with higher prevalence among infants born to Caucasian or non-Hispanic white mothers [3,7]. There are less well-defined associations with maternal drug use (illegal [e.g. cocaine, heroin] and legal [e.g. aspirin]), nutritional factors, smoking and occupations involving cooking. There may also be some association with environmental toxins like herbicides and pesticides, and with the presence of maternal infections, which include urinary tract infections and/or sexually transmitted infections $[1,3,8]$.

Evidence of regional or geospatial clustering of GS has also been described. Among years 2013 and 2018 geospatial primary and secondary clusters of CD were found by us in the Villa Clara province. In that study, specifically a secondary spatial cluster of GS was found in Manicaragua; located at the south-eastern of the Villa Clara province. It's a mountainous municipality where 59\% of its population lived in rural areas involved in agricultural land activities, mainly coffee and tobacco plantations. We surmised that this geographical cluster could be due to environmental exposures and further evaluation is necessary to assess this possibility [9]. Unlike OM, GS has little association with chromosomal abnormalities. Large series of fetal GS have shown chromosomal aneuploidy and additional unrelated fetal malformations in $1.2 \%$ and $12 \%$, respectively [5]. Most experts agree that the physiological midgut herniation is present between the $6^{\text {th }}$ and $11^{\text {th }}$ weeks of gestation and at crown-rump length of less than $45 \mathrm{~mm}$. However, there is $5 \%$ physiological midgut herniation could be observed at 12 weeks by three-dimension ultrasound (US) $[3,5,10]$.

The term omphalocele quite literally means swelling (kele) of the umbilicus (omphalos). The primary defect in OM is most likely a reduced prominence of the lateral body wall that does not provide sufficient space for the complete return of the intestines to the body cavity. After birth, the intestinal loops can be easily seen within an almost transparent sac consisting of amnion on the outside and peritoneal membrane on the inside $[3,10]$.

Spontaneous resolution of the first-trimester OM containing only the bowel was reported. A spontaneous resolution has not been observed in cases with the herniated liver [5]. The estimated prevalence of $\mathrm{OM}$ ranges from 1.0 to 2.0 per 10,000 live births, although the true incidence ( 1 in 3000 to 4000 ) and morbidity and mortality may be higher when elective abortions or fetal demises are taken into account $[2,7,11]$. In contrast to GS, prevalence studies of $\mathrm{OM}$ have reported either stable rates or modest increases over time $[6,7,12]$.

In contrast to GS, maternal economic and behavioural characteristics are not associated with OM. This CD is more frequently associated with young or advanced maternal age and with other associated anomalies including pulmonary hypertension, congenital heart defects, neural tube defects, and chromosomal abnormalities. When other anomalies are present, studies have shown a strong association with poor prognosis such as intrauterine fetal demise and preoperative neonatal death [1- 
3,13]. The presence or absence of the membranous sac aids in differentiating GS and OM, however, the membrane can rupture in the uterus. Ruptured OM has to be distinguished from a large GS. There are also a few cases of large GS (containing liver) that may be clinically difficult to differentiate from a ruptured OM [2]. In these cases, the differential diagnosis is depending on the umbilical cord insertion site: the umbilical cord insertion site is located in the umbilical sac in OM and paraumbilical in GS [2,7].

Since 1980, with the continuous improvement of the US equipment and technology, CD detected in the first and early second trimesters continued to increase. Routine prenatal screening and diagnosis of the AWD and any associated CD is paramount and considered standard of care. Early detection allows for prenatal genetic counselling and safe delivery at a tertiary care center with a multidisciplinary team involving neonatologists, obstetricians and pediatric surgeons [2,5]. Villa Clara province is in the central region of the Cuban archipelago, with a superficial extension of 8 $411,81 \mathrm{~km}^{2}$, occupying the fourth place among the fifteen Cuban provinces and representing $7.6 \%$ of the country's total landmass [14]. With this study we aimed to describe the prevalence trends of AWD, associated anomalies and chromosomal abnormalities in GS and $\mathrm{OM}$ cases, to provide an insight into the more affected system of organs and to describe fetal outcomes in both conditions.

\section{Patients and Methods}

This retrospective, observational study was performed from January 1990 to December 2019 with data obtained by the Cuban Registry of Congenital Malformations and by the Cuban Prenatal Congenital Malformations Registry (RECUMAC and RECUPREMAC respectively, for their names in Spanish), a multicenter, hospital and community-based registers, which recorded all pre- and postnatally detected congenital defects.

The RECUMAC and RECUPREMAC are nationwide registries which cover live births, fetal deaths from 20 weeks' gestational age and all terminations of pregnancy for any major CD. Their original records in the Villa Clara province are stored at the Provincial Medical Genetics Department (PMGD). We manually scrutinized all of them for the study time period. Data of the provincial statistical department, in the Villa Clara provincial health direction was consulted for population statistics, as the live births number per years.

We evaluated registered data from all diagnosed cases either with OM or GS which were coded by trained PMGD staff according to the $10^{\text {th }}$ revision of the International Statistical Classification of Diseases and Related Health Problems for Diagnoses (ICD-10), codes for the aforementioned CD are Q79.2 and Q79.3 respectively, [15] which are accompanied with a written description for each CD. The full universe of AWD data was used; no cases were withdrawn from the study. Due to the Cuban Registries include a textual description of all the observed CD performed either by US or by physical examination we avoid the bias of miscoding of the type of AWD, because GS and OM shared the same code before the version 10 of the International Classification of Diseases -ICD).

\section{Diagnostic Criteria}

For GS we included those cases which intestinal extrusion through a paraumbilical defects without a surrounding membrane and a normal umbilical cord insertion site; whereas for OM, cases with a median congenital herniation of viscera into the base of the umbilical cord after 12 weeks of gestation usually covered by a membrane, were included. For each case, the following numerical and categorical variables were obtained and analyzed: year of diagnosis, specific kind of AWD (GS, OM and others AWD) and the number and type of associated majors' CD. In the category "others AWD" those cases with diagnosis of Pentalogy of Cantrell (defects of the heart, pericardium, diaphragm, sternum, and AWD), ectopia cordis thoracis and OEIS complex (Acronym by: OM-Exstrophy of cloaca-Imperforate anus-Spinal defects), Body Stalk Anomaly (AWD, severe kypho scoliosis and a short or absent umbilical cord) or Limb-body wall Complex (AWD or thoraco-abdominoschisis, limb defects and craniofacial defects) were included [16].

All cases were classified in two classes: "isolated" when no other majors CD were observed neither by US nor by physical examination or autopsies and "associated" when another CD was pre or postnatally diagnosed. The associated majors CD were counted in each affected system. Associated minors CD were not included. The associated majors CD were classified in a regional categorization by system of organs in the following six categories: Cardiovascular, Respiratory, Central Nervous, Musculoskeletal, Gastrointestinal and Genitourinary.

Data about associated CD were obtained besides the detailed US and fetal echocardiogram from post-mortem reports of the Pathology Department in the Provincial Maternity Hospital "Mariana Grajales", where all anatomo-pathological macroscopic studies were performed.

A separate cytogenetics database confirmed the karyotypes, and an abnormal karyotype was defined as one known to be phenotypically significant. Chromosomal studies of the fetal or neonatal karyotypes, resulting from amniocentesis, chorionic villus sampling, or postnatal/postmortem studies, were performed in the Cytogenetic Laboratory of the Medical Genetics provincial department of the Villa Clara province, Cuba. Karyotyping with G banding was performed in those cases of AWD with associated findings on physical examination or diagnosed by prenatal US. The prevalence rate at birth of AWD was calculated by dividing the numerator (registered AWD cases of live birth, stillbirth or elective pregnancy terminations) by the denominator (total number of live 
births in the studied period). The prevalence rate was expressed as the number of cases per 10,000 live births.

Fetal outcome was stratified in three main categories: intrauterine fetal death, elective termination of pregnancy (TOP) and live births (LB). Data concerning long-term patient clinical outcomes is not available in the revised CD registers. Categorical variables were described by frequencies and percentages. We conduct a statistical hypothesis test on the basis of the results of the $\mathrm{Z}$ test to compare proportions. $\mathrm{P}$ value $<0.05$ was considered statistically significant. Statistical analysis was done using SPSS Version 22 software. This study is based on an analysis of existing registered data, which were anonymously collected, according the ethical issues on human investigations. Written informed consent was obtained of all mothers previously at the sample's obtaining for chromosomal studies. It was approved by the Ethical Committee of the Biomedical Research Unit of the Villa Clara Medical University, following the World Medical Association Declaration of Helsinki $[17,18]$.

\section{Results}

A total of 158 cases of AWD were recorded from 1990 to 2019 in Villa Clara, of these 93 (58.9\%) were GS, 53 (33.5\%) were OM, whereas $12 / 158$ (7.6\%) were others AWD (which are excluded from further analysis). The cases were ascertained from 193916 LB. The overall prevalence of AWD (per 10,000 LB) was 8.15, meanwhile the prevalence of GS and OM was 4.80 and 2.73, respectively. That is, one case of GS in $2085 \mathrm{LB}$, whereas OM was found in 1: $3658 \mathrm{LB}$. Figure 1 shows an increasing trend in the overall prevalence rate per 10,000 LB of AWD over the thirty studied years in Villa Clara, from 3.83 in 1990 to 7.47 in 2019. The GS prevalence was over the OM prevalence most years during the study timeframe. The peak of the prevalence of GS was 17.9 per 10,000 LB in 2006.

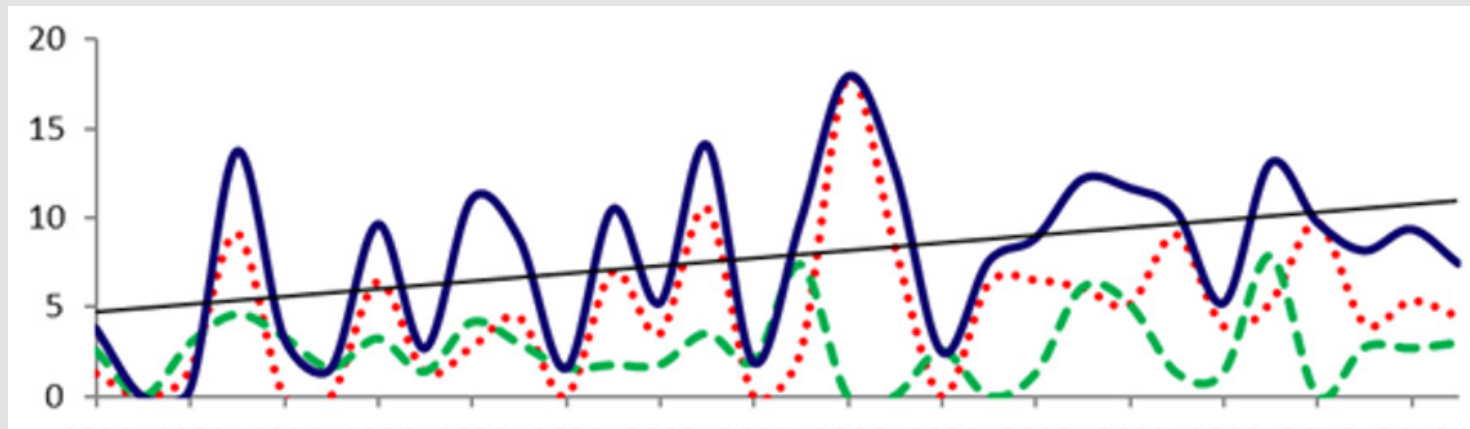

199019921994199619982000200220042006200820102012201420162018

Figure1: Prevalence trends of gastroschisis, omphalocele and the totality of congenital abdominal wall defects in Villa Clara, Cuba. 1990- 2019.

The majority of GS cases did not have additional anomalies (80/93 [86,0\%]). We observed a striking difference between the proportions of isolated GS and associated cases. (Z= 5, 47; $\mathrm{p}<$ 0.001). Meanwhile, (30/53 [56,6\%]) of OM cases had associated $\mathrm{CD}$, although, there were not statistically significant differences between these proportions ( $p=0,18)$. We identified 65 associated CD in 43/146 [29,5\%]) cases of GS and OM. In 13/93 [14\%]) of GS cases and in $30 / 53[56,6 \%])$ of OM cases at least one associated CD was observed (Table 1). Of the 43 cases with associated CD,
$13(30,2 \%)$ had more than one CD. OM cases were more likely to be diagnosed with at least one other CD than those with GS. This was true for most categories of involved system of organs, which all shown statistically significant differences, but respiratory and gastrointestinal. Gastrointestinal CD were the most frequent among GS cases $(4,30 \%)$, meanwhile among OM cases musculoskeletal and cardiovascular CD were the most prevalent with frequencies of $30,19 \%$ and $22,64 \%$ respectively (Table 2 ).

Table 1: Distribution of gastroschisis and omphalocele cases according the presence or not of associated congenital defects. Villa Clara, Cuba.1990- 2019.

\begin{tabular}{|c|c|c|c|c|c|c|}
\hline \multirow{2}{*}{ Type of AWD } & \multicolumn{2}{|c|}{ Isolated cases } & \multicolumn{2}{|c|}{ Associated cases } & \multirow{2}{*}{ Z } & \multirow{2}{*}{ p } \\
\cline { 2 - 6 } & No. & \% & No. & \% & & \\
\hline Gastroschisis $(\mathrm{n}=93)$ & 80 & 86.02 & 13 & 13.97 & 5,47 & $<0,001$ \\
\hline Omphalocele $(\mathrm{n}=53)$ & 23 & 43.39 & 30 & 56.6 & 0,89 & 0,18 \\
\hline
\end{tabular}

AWD: abdominal wall defects. No.: number of cases. \%: percent. Z: value of $Z$ in the hypothesis test. p: $p$ value 
Table 2: Frequency of associated congenital defects observed per system of organs in gastroschisis vs. omphalocele cases. Villa Clara, Cuba.1990- 2019.

\begin{tabular}{|c|c|c|c|c|}
\hline System of organs & Gastroschisis $\mathbf{n = 9 3}$ & Omphalocele $\mathbf{n = 5 3}$ & $\mathbf{Z}$ & $\mathbf{P}$ \\
\hline Cardiovascular & 1.08 & 22.64 & 4,20 & $<0,001$ \\
\hline Respiratory & 0 & 1.89 & 2,41 & 0,07 \\
\hline Central Nervous & 2.15 & 11.32 & 5,17 & $<, 01$ \\
\hline Musculoskeletal & 1.08 & 30.19 & 0,65 & 0,001 \\
\hline Gastrointestinal & 4.3 & 1.89 & 1,75 & 0,25 \\
\hline Genitourinary & 2.15 & 9.43 & 3,20 & $<03$ \\
\hline Abnormal karyotype & $\mathrm{NE}$ & 11.32 & & $<0,001$ \\
\hline
\end{tabular}

Frequency: percentage $\mathrm{n}$ : number of studied cases. $\mathrm{Z}$ : value of $\mathrm{Z}$ in the hypothesis test. $\mathrm{p}$ : $\mathrm{p}$ value. NE: not studied.

One-half of cases with associated CD affecting Central Nervous System had a Neural tube defects (4/8), where all cases were identified among $\mathrm{OM}$ cases and all the chromosomal abnormalities were observed among OM cases too (6/53 [11.3\%], including three cases with Trisomy 13, two cases with Trisomy 18 and a single case with Triploidy as is shown in Table 3.

In Table 3 comparisons among the results from present study and the literature of cases with GS and OM and the associated CD was shown.

Regarding fetal outcome, elective TOP took place in 131/146 cases $(89.7 \%)$, in $4 / 146$ intrauterine fetal death was described (2.7\%), 16/146 were LB (11.0\%). Six of these LB cases, (37.5\%) had prenatal diagnosis and parents decided to continue pregnancies.

Table 3: Comparison of present study and the literature of gastroschisis and omphalocele cases with associated congenital defects.

\begin{tabular}{|c|c|c|c|c|c|c|}
\hline $\begin{array}{c}\text { Studied Variables } \\
\text { Authors }\end{array}$ & $\begin{array}{l}\text { Stoll et al. [4] } \\
\text { France }\end{array}$ & $\begin{array}{c}\text { Corey et al. [27] } \\
\text { USA }\end{array}$ & $\begin{array}{l}\text { Corona et al. } \\
\text { [28] Mexico }\end{array}$ & $\begin{array}{c}\text { Watanabe et al. } \\
\text { [38] Japan }\end{array}$ & $\begin{array}{l}\text { Chukwue-meka et } \\
\text { al. [33] Nigeria }\end{array}$ & $\begin{array}{l}\text { Present study } \\
\text { (2021) Cuba }\end{array}$ \\
\hline \multicolumn{7}{|c|}{ Gastrosquisis } \\
\hline Total number of cases & 60 & 4687 & 108 & 11 & 39 & 93 \\
\hline With associated CD & 17 & 375 & 52 & 3 & 8 & 13 \\
\hline Cardiovascular & 10 & 35 & 3 & 0 & 1 & 1 \\
\hline Respiratory & 0 & 14 & 8 & 0 & 0 & 0 \\
\hline Central Nervous & 21 & 35 & 2 & 0 & 0 & 2 \\
\hline Neural tube defects & 2 & 5 & 1 & 0 & 0 & 0 \\
\hline Musculoskeletal & 14 & NA & 2 & 1 & 2 & 1 \\
\hline Gastrointestinal & 10 & 216 & 28 & 0 & 5 & 4 \\
\hline Genitourinary & 14 & 23 & 19 & 1 & 0 & 2 \\
\hline Others & 3 & NA & 1 & 1 & 0 & 4 \\
\hline Abnormal karyotype & 1 & 16 & NA & NA & NA & NA \\
\hline Trisomy 13 & 1 & 1 & NA & NA & NA & NA \\
\hline Trisomy 18 & 0 & 1 & NA & NA & NA & NA \\
\hline Others & 0 & 14 & NA & NA & NA & NA \\
\hline \multicolumn{7}{|c|}{ Omphalocele } \\
\hline Total number of cases & 86 & 1448 & NA & 8 & 40 & 53 \\
\hline With associated CD & 74 & 507 & NA & 7 & 13 & 30 \\
\hline Cardiovascular & 15 & 162 & NA & 2 & 1 & 12 \\
\hline Respiratory & 3 & 49 & NA & 0 & 0 & 1 \\
\hline Central Nervous & 9 & 58 & NA & 0 & 1 & 6 \\
\hline Neural tube defects & 7 & 27 & NA & 0 & 1 & 4 \\
\hline Musculoskeletal & 23 & NA & NA & 1 & 0 & 16 \\
\hline Gastrointestinal & 10 & 98 & NA & 1 & 2 & 1 \\
\hline Genitourinary & 17 & 80 & NA & 1 & 1 & 5 \\
\hline
\end{tabular}




\begin{tabular}{|c|c|c|c|c|c|c|}
\hline Others & 10 & NA & NA & 2 & 6 & 7 \\
\hline Abnormal karyotype & 25 & 87 & NA & 1 & 1 & 0 \\
\hline Trisomy 13 & 5 & 37 & NA & 0 & 0 & 3 \\
\hline Trisomy 18 & 17 & 35 & NA & 1 & 0 & 2 \\
\hline Others & 3 & 15 & NA & 0 & 1 & 1 \\
\hline
\end{tabular}

No.: Number of cases. NA: Not available (not mentioned or not studied).

\section{Discussion}

The prevalence rate of GS (per 10,000 births) during the study timeframe was twofold those of OM (4.8 and 2.7 respectively). It is consistent with trends widely described in the literature, where is stated that prevalence of GS in recent decades shows a worldwide remarkable and worrying increasing trend, suggesting a role of environmental factors $[1,8,12,19]$. From an incidence of $0.06-0.8$ per 10,000 in the 1960 s, GS has become more prevalent over the last few decades to its current rates of $4.5-5.13$ per 10,000 pregnancies [8]. The prevalence rates (per 10,000 LB) of GS and OM in our series are consistent with Schemedding [11] who reported 4-5 for GS and 2 for OM, and almost the same as Stalling [7] found for a larger series in the United States of America (USA) [4.3 for GS and 2.1 for $\mathrm{OM}]$.

The ratio of GS to OM of 1.8:1 seen in our study can be considered a reflection of the differences in incidence between the two conditions, as reported in the published literature, which shows that $\mathrm{OM}$ has an incidence rate approximately one-half that of GS and has been stable over time [13]. Otherwise, the lowest prevalence rates (per 10,000 LB) of GS worldwide had been described in Asian countries. In the Liaoning province in China, the prevalence of GS was 2.30 in a series of ten years of study and 0.50 in Taiwan and Japan, respectively [20-22]. Authors surmised that to a large extent, elective abortion may explain the lower incidence of the GS and AWD in Taiwan [20].

A higher OM prevalence was found over 22 years of data collection in the Wessex region of England and the Channel Isles, where 335 cases of OM from 614321 births were reported from 1994 to 2015, for a prevalence of 5.45 per 10,000 pregnancies [6]. In contrast to $\mathrm{OM}, \mathrm{GS}$ was rarely associated with a complex pattern of CD [4]. In the current study, $86 \%$ of GS were isolated and the remaining 14\% had associated CD; this is in agreement with other authors who have reported an incidence of associated anomalies in GS fluctuating from 5 to over 20\% [23-25]. Reported associations include cardiac abnormalities and increased prevalence of central nervous system anomalies, and limb and kidney anomalies and may influence the prognosis of the child with GS significantly [23]. In a study conducted by Given et al. [26] using data from 18 European congenital anomaly registries, they identified 1577 GS cases, $83.0 \%$ of which were isolated. The higher frequency of isolated GS cases than of those with associated CD has been shown in other series as well [27]. However, in a study conducted in a Mexican hospital, $52 / 108$ (48\%) of infants with GS had one or more associated anomalies, for 1.4 associated defects per case [28].

We found the most frequents associated anomalies in GS cases affected the gastrointestinal system, mainly intestinal atresia and necrosis. Intestinal atresia has been reported in up to $25 \%$ of GS cases in some series, and especially when the bowel was thickened and coated [25]. Likewise, in a study conducted by Lap and colleagues in the Netherlands they found that the most common additional gastrointestinal disorder was bowel atresia, accounting for $94.7 \%$ (18/19) of cases with complex GS, whereas the remaining case had perforation of the proximal jejunum without atresia [23]. Our finding of predominant associated major anomalies involved the gastrointestinal tract in GS cases is also consistent with a previously reported series [11] and it's similar to those found by researchers from Mexico, Nigeria and by far from USA (shown in Table 3), nevertheless in France the most frequent associated CD in GS cases were those affecting Central Nervous System, and in the series of eleven GS cases from a single hospital in Japan none had other associated gastrointestinal CD.

Similar to prior reports, we observed that $\mathrm{OM}$ cases were more frequently diagnosed with associated CD compared with those with GS [27] Musculoskeletal and cardiac anomalies were the most prevalent associated CD found in OM cases in our study, which is consistent with the literature, where its claimed that neonates with OM have higher rates of death compared to neonates with GS, this difference in mortality is thought to be related to the high incidence of associated CD and specifically, cardiac abnormalities among neonates with OM [29]. In our series, 57\% of OM cases had associated CD. These findings are consistent with other reports of prenatal diagnosis and management of $\mathrm{OM}$ where is stated that about $40-80 \%$ of all OM cases would have at least one concurrent anomaly. Reported associated anomalies include cardiac (7-47\%), gastrointestinal (3-20\%), genitourinary (6-20\%), chromosomal (3-20\%), musculoskeletal (4-25\%) and central nervous system (4-30\%). Authors stated that it is more common to find these additional anomalies in cases of small defects rather than when a giant OM [2].

In an study conducted by Corey, et al. [27] evaluating data from all infants diagnosed with either GS or OM discharged from 348 
neonatal intensive care units in North America, managed by the Pediatrix Medical Group from 1997-2012, they found 162 cases with an associated congenital heart defect from $507 \mathrm{OM}$ cases, as it's shown in the comparison among dissimilar AWD researches from six different countries. There is a known association between genetic disease and OM [27]. We found 11\% of chromosomal aberrations among OM cases. This frequency is quite lower than the reported in a single-center study of AWD prenatally diagnosed, where chromosomal abnormalities were found by karyotype in 8/29 (28\%) fetuses with OM [30]. In our study all cases with abnormal Karyotypes had numerical chromosomal aberrations (five cases with autosomal aneuploidy and a single case of polyploidy) and interestingly we don't find any case with structural chromosomal aberrations. It could be caused by the fact that in our province karyotyping is not performed to all OM cases, but those with pre or postnatal diagnosis of multiple associated CD or those cases diagnosed by US in mothers with advanced maternal age, whom have highest risk for chromosomal aneuploidies. No chromosomal study was performed to GS cases.

In contrast to our findings, in a study conducted by Zork and other Americans researchers, of the OM cases with abnormal karyotypes trisomy $18(\mathrm{n}=8)$ was the most common, followed by single cases of trisomy 13, triploidy, trisomy 2 mosaic, and a structural chromosomal aberration: 46,XX,del(5)(q13q22) mosaic [31]. Chromosomal aberrations such as trisomy 13 and 18 frequently accompany OM. Certain prenatal US findings can predict an associated chromosomal aberration, for example, an intracorporeal liver has a higher association with an abnormal karyotype than an extracorporeal liver. Furthermore, a small defect is more likely to be associated with an abnormal karyotype, by other hand; the presence of multiple CD increases the risk of chromosomal abnormalities [31,32]. Children with OM have more than $50 \%$ risk of having an associated anomaly, and about $50 \%$ of these have a chromosomal aberration such as trisomy $13,14,15$, 18 and 21 [33].

Among all abnormal karyotypes in our study we didn't find any Down syndrome (trisomy 21) or Turner syndrome (monosomy $\mathrm{X}$ ) among the OM cases. However, when twenty-six consecutive fetuses with a sonographically detectable OM and known karyotype were reviewed by Nyberg in the Swedish Medical Center, Seattle, Washington, USA; chromosomal abnormalities were found in 10 cases $(38 \%)$ from trisomy $18(n=4)$, trisomy $13(n=4)$, trisomy $21(n=1)$, or monosomy X $(n=1)$ [32]. It is important to note that even in the setting of a normal karyotype, at least $50 \%$ of cases with OM may have other CD (i.e. musculoskeletal and cardiovascular). Most cases of GS and OM were prenatally diagnosed in Villa Clara from 1990 to 2019, and around 90\% of parents opted for the elective TOP, whereas in this timeframe intrauterine fetal death was described in around 3\% of cases. The fetus with GS is at risk for complications such as intrauterine growth restriction, preterm delivery, and even intrauterine fetal demise [6]. Meanwhile in OM, the main prognostic factor in the patient outcome is the presence and severity of associated $\mathrm{CD}$, although size of defect, prematurity and sac rupture also have a role to play [3].

In many low and middle-income countries, the reported mortality of these malformations is $30-100 \%$, while in high-income countries; mortality in infants with AWD reaches less than 5\% [33]. A study conducted in Jamaica showed a frequency of death from GS of $79 \%$, meanwhile in Uganda, death frequency was $98 \%$ of cases $[12,34]$. AWD are life-threatening malformations with significant morbidity, mortality, and prolonged hospitalization, which require multidisciplinary expertise for their repair and management. Some parents may choose abortion because of their anxiety when counseled about the possibility of gastrointestinal discomfort or other associated CD. A high rate of TOP is associated with the prenatal diagnosis of AWD, which in turn affects the prevalence at birth of these CD [20]. Most cases of OM result in high rates of TOP and/or fetal loss. Because of the $\mathrm{OM}$ association with chromosomal aberrations and other severe CD potentially leading to TOP, over $85 \%$ of those with a chromosomal aberration were terminated in a study of birth prevalence and survival in England and Wales $[33,35]$.

The surgical outcomes of the isolated AWD without associated chromosomal or structural abnormalities appear to be good; however, a very high rate of TOP is associated with AWD, which may affect the parents' evaluation of the prognosis of the AWD [20]. In the Cuban population there is a marked tendency to choose TOP as a reproductive preventive choice facing the unequivocal identification of fetal life-threatening $\mathrm{CD}$, conditioned by its reliance in the health system because of abortions are performed of a secure, free and institutional way. Likewise, in the Netherlands in up to $74 \%$ of cases of $\mathrm{OM}$, depending on the presence of associated anomalies and gestational age at diagnosis, the pregnancy is terminated [36]. Lakasing in a large study of 445 prenatally diagnosed OM in a single unit over a 10 -year period found that less than $10 \%$ reached operative repair due to the recognized high TOP and fetal death rate [37]. Although there is a high-TOP rate for fetuses with AWD, the surgical outcome for isolated AWD without structural or chromosomal abnormalities is good and overall survival rates is greater than $80 \%[20,38]$.

To the best of our knowledge this is the first study conducted in Cuba including a large series of years to determine the frequency and type of associated congenital anomalies in GS and OM cases. The major strength of the current study was the high quality of Cuban's hospital and community-based CD registries with reliable prenatal and postnatal information and absence of unregistered cases. Besides, Cuban Registries include a textual description of all 
the observed CD performed either by US or by physical examination then, the bias of miscoding the type of AWD by using ICD- 9 or ICD-10 codes is inexistent. There are three limitations to our study: The first is the lack of data regarding number of stillbirths during the study timeframe, for that reason when prevalence rate was estimated, in the denominator only LB were included; the second limitation is that chromosomal studies was not performed to the totality of the AWD cases, and the thirst limitation is the non-availability of data concerning to long-term patient clinical outcomes in the CD registers.

In conclusion, a rise in AWD prevalence has been noted in recent decades in Villa Clara province. The present study revealed that majority of GS cases did not have additional anomalies; meanwhile $\mathrm{OM}$ cases were more likely to have other $\mathrm{CD}$, predominantly in musculoskeletal and cardiovascular systems, besides chromosomal aberrations. In our study a very high rate of TOP is observed among AWD cases.

\section{Acknowledgements}

The authors thank Gisela Noche González MD from the Villa Clara PMGD for her assistant in obtaining RECUMAC and RECUPREMAC data. We also thank the genetics counselors of Villa Clara province's 13 municipalities, who assess all newborns at one month and three months of age in primary healthcare centers and contribute to the countrywide congenital abnormality resgistry. Authors are grateful too for the valuable comments and statistical assistance provided by Roberto Lardoeyt Ferrer $\mathrm{PhD}$ from the Havana Medical University, Cuba.

\section{References}

1. Feldkamp ML, Arnold KE, Krikov S, Reefhuis J, Almli LM, et al. (2018) Risk of gastroschisis with maternal genitourinary infections: the US National birth defects prevention study 1997-2011. BMJ Open 9: e026297.

2. Verla MA, Style CC, Olutoye OO (2019) Prenatal diagnosis and management of omphalocele. Sem Ped Surgery 28(2): 84-88.

3. Kelay A, Durkin N, Davenport M (2016) Congenital anterior abdominal defects. Paediat Surgery 34 (12): 621-627.

4. Stoll C, Alembik Y, Dott B, Roth MP (2008) Omphalocele and gastroschisis associated malformations. Am J Med Genet Part A 146A(10): 1280-1285.

5. Ding WP, Li N, Chen M (2020) Ultrasound screening of fetal anomalies at 11-13+6weeks. Mat Fetal Med 3(1): 175-180.

6. Safrida EN, Anggraini A, Wibowo T, Wandita S, Haksari EL (2020) Discharge outcomes of liveborn infants with omphalocele (Isolated Vs non-isolated). Mal J Med Health Sci 16(SUPP3): 37-42.

7. Stalling EB, Isenburg JL, Short TD, Heinke D, Kirby RS, et al. (2019) Population-based birth defects data in the United States, 2012-2016: A focus on abdominal wall defects. Birth Defects Res 111(2): 1436-1447.

8. Melov SJ, Tsang I, Cohen R, Badawi N, Walker K, et al. (2018) Complexity of gastroschisis predicts outcome: epidemiology and experience in an Australian tertiary centre. Pregnancy and Childbirth 18(1): 222.
9. Taboada LN, Herrera MM, Hernández GG, Ledesma HH (2020) Geospatial and temporal clustering of folic acid- sensitive congenital defects in Villa Clara Province, Cuba. Biomed J Sci \& Tech Res 29(5): 22818-22826.

10. O' Rahilly R (1978) The timing and sequence of events in the development of the human digestive system and associated structures during the embryonic period proper. Anat Embryol 153: 123-136.

11.Schmedding A, Wittekind B, Salzmann-Manrique E, Schloesser R, Rolle U (2020) Decentralized surgery of abdominal wall defects in Germany. Pediat Surg Internat 36: 569-578.

12. Marshall NSG, Fearon KM, Gill MI, DeSouza CJ, FearonIC, et al. (2017) Mortality-related factors in gastroschisis - a Jamaican perspective. J Ped Surgery 52(4): 530-533.

13. Hibbs SD, Bennett A, Castro Y, Rankin KM, Collins JW (2016) Abdominal wall defects among Mexican American infants: The effect of maternal nativity. Ethn Dis 26(2): 165-170.

14. (2020) Villa Clara Statistical Year Book. National Office of Statistic and Information. ONEI.

15. (2018) Panamericam Health Organization International Statistical Classification of Diseases and Related Health Problems.10th revision. Washington, D.C: OPS.

16. Lyons JK (2006) Chromosomal abnormality syndromes. En: Smith's Recognizable patterns of human malformations. $6^{\text {th }}$ (edn.). Philadelphia: Elsevier Saunders.

17. Taboada Lugo N (2017) El consentimiento informado en la práctica asistencial e investigativa de la Genética Clínica. Acta Med Centro 11(3): 88-100.

18. (2017) Helsinki's Declaration. World Medical Association.

19. Wissanji H, Puligandla PS (2018) Risk stratification and outcome determinants in gastroschisis. Sem Ped Surgery 27: 300-303.

20. Chen MC, Chen JH, Chen Y, Tsai YH, Lee CH (2019) Low and decreased prevalence of congenital abdominal wall defect in Taiwan. J Pediat Surg 54(9): 1958-1964.

21. Li N, Chen YL, Li J, Li LL, Jiang CZ, et al. (2016) Decreasing prevalence and time trend of gastroschisis in 14 cities of Liaoning Province: 2006-2015. Scient Reports 6(1): 33333.

22. Suita S, Okamatsu T, Yamamoto T, N Handa, Yuji N, et al. (2000) Changing profile of abdominal wall defects in Japan: results of a national survey. J PediatrSurg 35(1): 66-71.

23. Lap CC, Brizot ML, Pistorius LR, Kramer WL, Teeuwen IB, et al. (2016) Outcome of isolated gastroschisis; an international study, systematic review and meta-analysis. Early Human Develop 103: 209-218.

24. Tadepally K, Gattu V, Vellanki S (2018) Gastroschisis and spine abnormality in fetus. Med J DY PatilVidyapeeth 11(1): 75-77.

25. Beaudoin S (2018) Insights into the etiology and embryology of gastroschisis. Sem Ped Surgery 27: 283-288.

26. Given JE, Loane M, Garne E, Nelen V, Barisic I, et al. (2017) Gastroschisis in Europe-A case-malformed-control study of medication and maternal illness during pregnancy as risk factors. Paed Perinatal Epidemiol 31(6): 549-559.

27. Corey KM, Hornik CP, Laughon MM, McHutchison K, Clark RH, et al. (2014) Frequency of anomalies and hospital outcomes in infants with gastroschisis and omphalocele. Early Hum Dev 90(8): 421-424.

28. Corona RJR, Nieto GR, López ME, Marure E, Cárdenas RJJ, et al. (2016) Associated congenital anomalies in infants with isolated gastroschisis: A single-institutional experience. Am J Med Genet Part 170(2): 316-321. 
29. Raymond SL, Downard CD, St Peter SD, Baerg J, Qureshi FG, et al. (2019) Outcomes in omphalocele correlate with size of defect. Sem Ped Surgery 54(8): 1546-1550.

30. Hidaka N, Murata M, Yumoto Y, Hojo S, Fujita Y, et al. (2009) Characteristics and perinatal course of prenatally diagnosed fetal abdominal wall defects managed in a tertiary center in Japan. J Obstet Gynaecol Res 35(1): 40-47.

31. Zork NM, Pierce S, Zollinger T, Kominiarek MA (2014) Predicting feta karyotype in fetuses with omphalocele: the current role of ultrasound. J Neonatal Perinatal Med 7(1): 65-69.

32. Nyberg D, Fitzsimmons J, Mack LA, Hughes M, Pretorius DH, et al. (1989) Chromosomal abnormalities in fetuses with omphalocele. Significance of omphalocele contents. J Ultrasound Med 8(6): 299-308.

33. Chukwuemeka ALJ, Ajayi NA, Rolle U (2020) Major abdominal wall defects in the lowand middleincome setting: current status and priorities. Pediatr Surg Int 36(5): 579-590.

ISSN: 2574-1241

DOI: 10.26717/BJSTR.2021.36.005854

Noel Taboada Lugo. Biomed J Sci \& Tech Res

(C) This work is licensed under Creative Commons Attribution 4.0 License

Submission Link: https://biomedres.us/submit-manuscript.php
34. Wesonga AS, Fitzgerald TN, Kabuye R, Kirunda S, Langer M, et al. (2016) Gastroschisisin Uganda: opportunities for improved survival. J Pediatr Surg 51(11): 1772-1777.

35. Springett A, Draper ES, Rankin J, Catherine R, David T, et al. (2014) Birth prevalence and survival in England and Wales: 2005 to 2011. Birth Defects Res A Clin Mol Teratol 100(9): 721-725.

36. Peters NCJ, Hijkoop A, Lechner RL, Eggink AJ, van Rosmalen J, et al. (2019) The validity of the viscera abdominal disproportion ratio for type of surgical closure in all fetuses with an omphalocele. Prenatal Diagnosis 39(10): 1070-1079.

37. Lakasing L, Cicero S, Davenport M, S Patel, Kypros HN (2004) Current outcome of antenatally diagnosed exomphalos: an 11-year review. J Pediatr Surg 41(8): 1403-1406.

38. Watanabe S, Suzuki T, Hara F, Yasui T, Uga N, et al. (2017) Omphalocele and gastroschisis in newborns: Over 16 years of experience from a single clinic. J Neonatal Surg 6(2): 27.

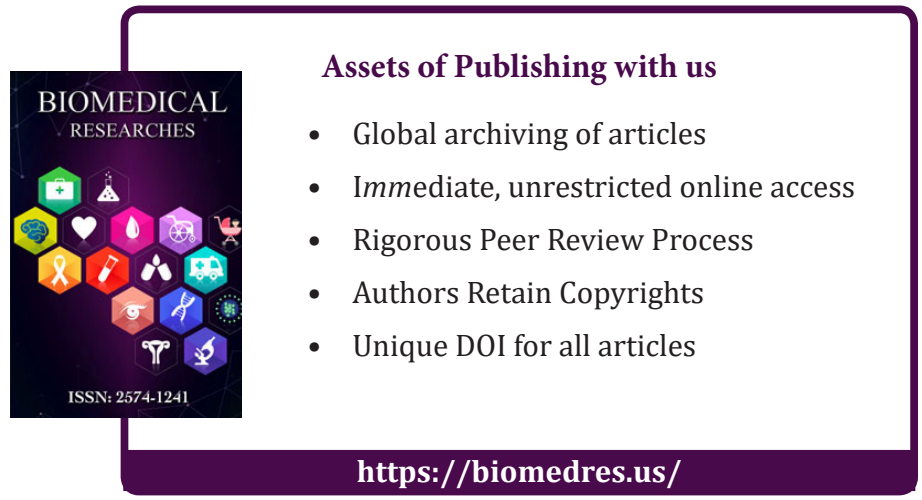

